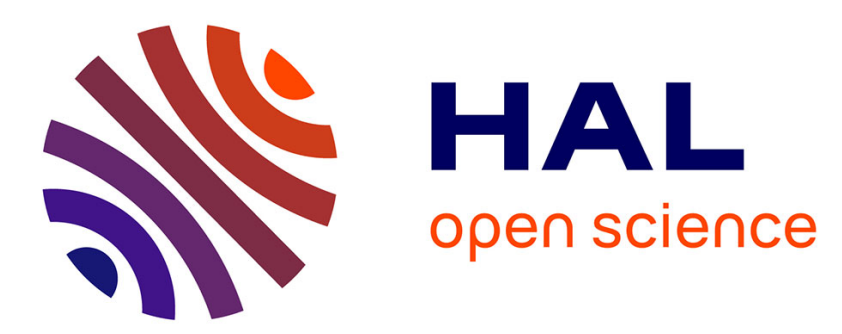

\title{
An Ex Situ Reflection Mode XANES Study of Underpotentially Deposited Copper Monolayers
}

\author{
P. Borthen, H.-H. Strehblow
}

\section{To cite this version:}

P. Borthen, H.-H. Strehblow. An Ex Situ Reflection Mode XANES Study of Underpotentially Deposited Copper Monolayers. Journal de Physique IV Proceedings, 1997, 7 (C2), pp.C2-695-C2-696. 10.1051/jp4:1997207 . jpa-00255153

\section{HAL Id: jpa-00255153 https://hal.science/jpa-00255153}

Submitted on 1 Jan 1997

HAL is a multi-disciplinary open access archive for the deposit and dissemination of scientific research documents, whether they are published or not. The documents may come from teaching and research institutions in France or abroad, or from public or private research centers.
L'archive ouverte pluridisciplinaire HAL, est destinée au dépôt et à la diffusion de documents scientifiques de niveau recherche, publiés ou non, émanant des établissements d'enseignement et de recherche français ou étrangers, des laboratoires publics ou privés. 


\title{
An Ex Situ Reflection Mode XANES Study of Underpotentially Deposited Copper Monolayers
}

\author{
P. Borthen and H.-H. Strehblow \\ Institut für Physikalische Chemie und Elektrochemie, Heinrich-Heine-Universität Düsseldorf, \\ Universitätsstrasse 1, 40225 Düsseldorf, Germany
}

\begin{abstract}
Reflection mode XANES was performed ex situ on a copper monolayer underpotentially deposited onto a polycrystalline gold electrode. According to calculations based on reference substances, the thickness of the adsorbate layer was $0.21 \mathrm{~nm}$ and its oxidation state was close to +1 . The ex situ spectra were found to be very similar to the previously published in situ data indicating that the adsorbate layer on the electrode surface does not significantly change after the removal from the electrolyte. The results showed that the reflection mode XAS is well suited for the study of adsorbate systems.
\end{abstract}

\section{Introduction}

Underpotential deposition (UPD) is a simple electrochemical method for the formation of thin adsorbate layers on electrode surfaces [1]. UPD deposits can form ordered submonolayers up to monolayer structures. To our knowledge, all previous $x$-ray absorption studies on UPD layers were performed by detection of the fluorescence radiation (e.g. [2-6]). However, the reflection mode XAS i.e. the variation of the $\mathrm{X}$-ray reflectivity in the vicinity of an absorption edge can also be used in order to obtain the desired information. Previous calculations have shown that this detection mode should have a submonolayer sensitivity [7]. In contrast to the fluorescence detection, the measured x-ray reflectivity can simply be correlated to the absolute amount of the adsorbate present on the surface. Additionally, the evaluation of the $x$-ray reflectivity spectra yield the roughness of the electrode surface. The aim of this preliminary work was to test the possibility of the grazing incidence reflection mode XAS to provide valuable spectra from adsorbate systems.

\section{Experimental}

The substrate for the copper deposition was a $100 \mathrm{~nm}$ thick gold layer vapour deposited onto a $3 \times 5 \mathrm{~cm}^{2}$ float glass plate. The electrolyte was $0.05 \mathrm{M} \mathrm{H}_{2} \mathrm{SO}_{4}$ containing $1 \times 10^{-3} \mathrm{M} \mathrm{CuSO}_{4}$. The electrolyte was saturated with air during the deposition. The electrochemical potential at which the underpotential deposition was performed was $+200 \mathrm{mV}$ (vs. NHE); the electrode was held at this potential for $200 \mathrm{~s}$ and subsequently withdrawn from the electrolyte solution in order to perform the XAS measurement. The anodic stripping charge for a similar deposition performed directly before that used for the XAS measurement was $200 \mu \mathrm{C}$, a value very near to that for $\mathrm{C} \mathrm{Cu}^{+1}$ monolayer on $\mathrm{Au}(111)$ surface $(190 \mu \mathrm{C})$. The experiment was performed at the HASYLAB RÖMO 2 station (bending magnet) using the x-ray reflectometer build in our home laboratory [8] and a detector system consisting of three ionisation chambers. The reflection mode XAS measurement was perfomed at a glancing angle of 0.45 degrees i.e. in the vicinity of the critical angle for gold. The critical angle is the angle at which the step in the reflectivity curve has a maximum due to the adsorbed overlayer: This was additionally confirmed by numerical simulations for different $\mathrm{Cu} / \mathrm{Au}$ systems. The irradiated electrode surface was about $1 \mathrm{~cm}^{2}$ and the total integration time was $1 \mathrm{~h}$ with a mean DORIS current of $90 \mathrm{~mA}$.

\section{Results}

The energy dependent $x$-ray reflectivity measured for the UPD copper monolayer on polycristalline gold is shown in the upper part of figure 1. The lower part of this figure shows the spectrum calculated for a system consisting of $0.21 \mathrm{~nm} \mathrm{Cu}_{2} \mathrm{O}$ on gold. The thickness of the copper oxide layer used for these calculations was choosen in order to achieve a best fit to the measured reflectivity step in the vicinity of the $\mathrm{Cu}$ absorption edge; The thickness of $\mathrm{a} \mathrm{Cu}_{2} \mathrm{O}$ monolayer is $0.22 \mathrm{~nm}$. The calculations started with the data obtained in the transmission mode with $\mathrm{Au}$ and $\mathrm{Cu}$ foils and $\mathrm{CuO}$ and $\mathrm{Cu}_{2} \mathrm{O}$ reference substances. Using these reference data, the real part of the complex, energy dependent refractive index $n(E)=1-\delta-i \beta$ was obtained by Kramers-Kronig transform [9]. The $\mathrm{x}$-ray reflectivities for layer system consisting of copper species on gold were calculated using the recursive algorithm described in [10]. 
The comparisons of the background substracted measured spectrum with the spectrum calculated for the system $\mathrm{Cu}_{2} \mathrm{O} / \mathrm{Au}$ is shown in figure 2 . The best fit to the measured spectrum was obtained with the assumed rms (root mean squared) surface roughness of $2.4 \mathrm{~nm}$. The most striking feature of the measured spectrum is the absence of the edge peak at about $8982 \mathrm{eV}$ which is characteric for metallic copper and copper(I)-oxide. This indicates that no metallic copper or copper(I)-oxide bulk phase has formed on the gold surface. However, according to the position of the measured reflectivity edge (figure 2) the ex situ oxidation state of the copper atoms adsorbed on the gold surface is close to +1 , a result very similar to that found in situ by Tadjeddine et $a l$.[3]. Additionally, the similarity of the ex situ spectrum showed in figure 2 with published spectra measured in situ [3,6] suggest that the adsorbed copper monolayer deos not significantly change after removal from the electrolyte: This is probably due to coadsorbed sulfate $\left(\mathrm{SO}_{4}^{-2}\right)$ or bisulfate $\left(\mathrm{HSO}_{4}^{-1}\right)$ ions [11] which seem to preserve copper adatoms from further oxidation.

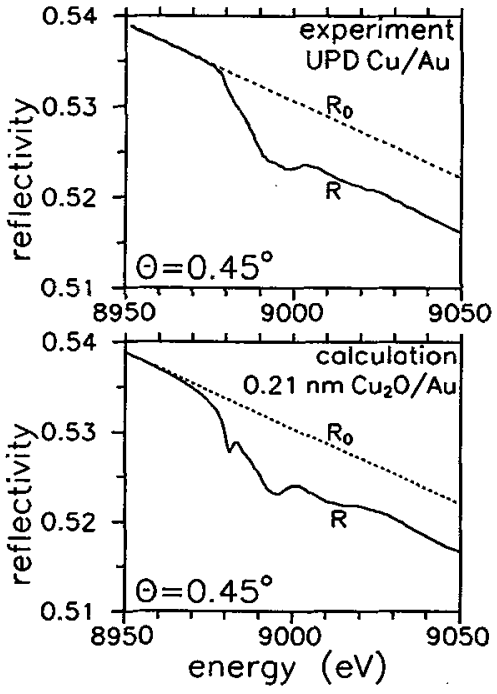

Figure 1: Reflectivity measured ex situ in the vicinity of the Cu-Kedge for the UPD copper layer on gold (top) and the calculation for the system consisting of $0.21 \mathrm{~nm} \mathrm{Cu_{2 }} \mathrm{O} / \mathrm{Au}$ (bottom).

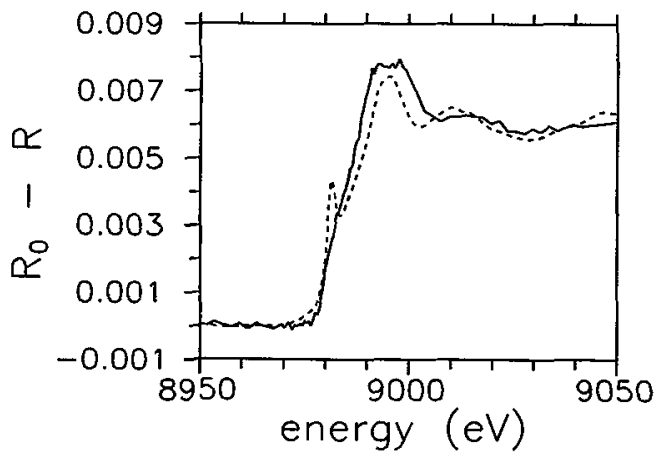

Figure 2: Direct comparison of the measured (solid) and the calculated (dashed) reflectivity edges from figure 1.

\section{Conclusions}

- monolayer sensitivity with XAS in the reflection mode can be easily achieved;

- the comparison of the reflectivity data with calculations yields the amount of the adsorbate and its oxidation state;

- the ex situ oxidation state of the copper adatoms on polycrystalline gold surface is close to +1 ;

- the adsorbate system on the electrode surface seems to be preserved after the emersion of the electrode from the electrolyte;

- ex situ results are very similar to those obtained by in situ measurements on $\mathrm{Au}(100)$ and polycrystalline Pt.

\section{Acknowlegdments}

The help of D. Hecht and D. Lippkow during the experiments at HASYLAB is greatly acknowledged.

\section{References}

[1] Kolb D., Adv. Electrochem. Electroch. Ing. 11 (1974) 125-271

[2] Blum L., Abruña H.D, White J., Gordon II J.G., Borges G.L., Samant M.G. and Melroy O.R., J. Chem. Phys. 85 (1986) 6732-6738

[3] Tadjeddine A., Tourillon G. and Guay D., Electrochimica Acta 36 (1991) 1859-1862

[4] Yee S.H. and Abruña H.D., J. Phys. Chem. 97 (1993) 6278-6288

[5] Tadjeddine A., Lahrichi A. and Tourillon G., J. Electroanal. Chem. 360 (1993) 261-270

[6] Furtak T.E., Wang L., Pant J., Pansewicz K. and Hayes T.M., J. Electrochem. Soc. 141 (1994) 2369-2373

[7] Gurman S.J. and Fox R, Philosophical Magazine: B 54 (1986) L45-L49

[8] Borthen P. , PhD-Thesis (Düsseldorf, 1996)

[9] Borthen P. and Strehblow H.-H., Physica B 208\&209 (1995) 421-422

[10] de Boer D.K.G., Phys. Rev. B 44 (1991) 498-511

[11] Toney M.F., Howard J.N, Richter J., Borges G.L., Gordon J.G., Melroy O.R., Yee D. and Sorensen L.B., Phys. Rev. Lett. 75 (1995) 4472-4475 